NBER WORKING PAPERS SERIES

\title{
THE EFFECTS OF PENSIONS AND RETIREMENT POLICIES ON RETIREMENT IN HIGHER EDUCATION
}

Alan L. Gustman

Thomas L. Steinmeier

Working Paper No. 3593

\author{
NATIONAL BUREAU OF ECONOMIC RESEARCH \\ 1050 Massachusetts Avenue \\ Cambridge, MA 02138 \\ January 1991
}

We are grateful for data provided by Katherine $H$. Hanson of the Consortium for Financing Higher Education, to Euysung Kim, scott Miller and Fony Suryapranata for able research assistance, to Steven Venti, olivia Mitchell and $w$. Lee Hansen for comments, and to The Department of Education for research support. This paper is part of NBER's research program in Labor studies and Aging. Any opinions expressed are those of the authors and not those of the National Bureau of Economic Research. 
NBER Working Paper \#3593

January 1991

\title{
THE EFFECTS OF PENSIONS RND RETIREMENT POLICIES
}

ON RETIREMENT IN HIGHER EDUCATION

\begin{abstract}
A structural retirement model is estimated using data for tenured, male faculty employed in the 1970's at $26 \mathrm{high}$ quality private colleges and universities. Simulations of raising and then abolishing the mandatory retirement age suggest very large increases in full time work by faculty members in their late 60's and early 70 's. Simulations also suggest that early retirement incentive programs would offset only a small fraction of the increase in work due to changes in mandatory retirement, and that rents created by these programs exceed savings from induced early retirements, with salaries of replacements further adding to costs.

Alan L. Gustman

Loren M. Berry Professor of Economics Department of Economics Dartmouth College Hanover, NH 03755

Thomas I. Steinmeier Department of Economics Texas Tech University Lubbock, TX 79409
\end{abstract}


The Effects of Pensions And Retirement Policies On Retirement In Higher Education. By Alan L. Gustman and Thomas L. Steinmeier*

Exits through retirement are one of the Lmportant labor market flows which shape the age structure of faculty, and help to determine the quality and costs of higher education. As a result of perceived pressures from demographic changes, as well as in reaction to a series of policy initiatives, including a legal requirement that mandatory retirement be eliminated in higher education after 1993, institutions of higher education have become increasingly interested in predicting and influencing retirement behavior of faculty, while exerting more control over the associated costs of compensation.

Life cycle, structural econometric models of retirement have been used to analyze analogous policy issues at the national level fFields and Mitchell, 1984. Gustman and Steinmeier, 1986a, Lunsdaine, Stock and wise, 1990). These models first specify and estinate the various components of the opporturity set. Then, based on the subsequent retirenent behavior of those facing alternative opportunities, the parameters of the utility function which underlie the retirement decision are estimated. Once the components of a struccural retirement nodel are estimated, effects on retirement ourcomes of policy changes nay be simulated (e.g., Gustman and Steinmeier, 1985, $1986 b$ and forthcoming).

In the present paper, we apply these techniques to analyze retirement behavior of the tenured, male faculty employed or retiring in the late 1970's at 26 member colleges and universities of the Consortium on Financing Higher Education (COFHE), a group which includes some of the highest quality private colleges and universities in the country. The estimated model is used to analyze the effects of early retirement incentives and changes in mandatory recirement rules. Although the sample is not fully representative of higher education, and the data are over a decade old, these are the best data available 
for illustrating the usefulness of the recent developments in retirement research in analyzing related behavior and policies in higher education.

\section{The Empirical Epecification And Data}

The utility function to be estimated is CES and is given by:

$$
u=(1 / \delta) \int_{0}^{T}\left([C(t)]^{\delta}+e^{x} t^{\beta+\epsilon}[L(t)]^{\delta}\right) d t
$$

where $C(t)$ and $L(t)$ are consumption and leisure at time $t$, and $T$ is the relevant time horizon. $x_{t}$ includes age and a constant, which affect the relative weight of leisure in the utility function at time $t$, and $\beta$ is the associated vector of parameters, which is presumed to be constant across both time and individuals, $\delta$ (with $\delta \leq 1$ ) and $\epsilon$ are time-invariant stochastic terms reflecting, respectively, the elasticity of substitution between consumption and leisure for each individual and the relative weight that the individual places on leisure.

This utility function is maximized with respect to consumption and leisure, subject to the lifetime budget constraint

$$
\int_{0}^{T} e^{-r t}\{y[L(t), t]-C(t)\} d t=0
$$

where $y[$.$] is the function relating compensation to leisure (and hence to work$ effort), and $r$ is the real interest rate. The compensation function reflects the effects of wages, pensions, and social security, with the effects of pensions and social security calcuiated as the difference in the present value of benefits attributable to additional work.

The deta used in the structural retirement analysis pertain to arts and sciences faculty employed by these schools on December 31, 1978, to retirees from these schools from the 1973-74 academic year through the end of 1978, and to the pensions and retirement programs reported by these schools in August, 
1979. For each faculty member employed over the covered period, the following information is provided in the survey: date of birth; sex; date of entry into tenured track status; indicators of tenure status: date of tenure; nine-month salary zate; full or part-time status; date of retirement, departure or ternination, if appropriate; whether, in the case of a departure, it was due to mandatory retirement; and other information about the faculty member. Importantly, however, no information is available on health status. Each school is identified. For the 1979 period, pension plan provisions, early retirement and flexible retirement policies are reported for each school in separate coFHE documents. (These data have also been used by Blackburn and Schiffman, 1980, and Southworth and Jagmin, 1979). For later simulations, we have obtained descriptions of these plans for 1989 directly from the schools.

In constructing the opporturity set, wage equations for full and part-time work axe estinated. (These equations are available in a statistical appendix which will be supplied by the atiors upon request. y wages are projected using the experience and temure coefficients from the wage equations, assuning a general wage growth equal to the growth of average hourly earnings ationally. Social security benefits are calculated on the basis of the rules that were applicable to each cohort (see Gustman and Steineier, 1985). The calculations include retired worker benefits, spouse benefits, and survivor benefits. Required faculty pension contributions are subtracted from wages.

In 1979, normal retirement (NR) age was 65 in 18 of the COFHE schools in the sample, 66 in 1, 68 in 5, and 70 in 2. From 1979 to 1989, the median normal retirement age remained at 65 , but five schools reduced the normal retirement age from 70 or 68 to 65 . Mandatory retirement (MR) age was 65 in 5 schools, 68 in 5 schools, 70 in 9 schools, and 7 did not report a mandatory retirement age. By 1989, mandatory retirement age was 70 at all 26 schools. Separate information is also provided on the actual application of mandatory retirement to each of 
the cases in the sample (Southworth and Jagmin, 1979). Table 1 indicates by age range the percentages of retirements which were mandatory.

At sever schools, early retirement (ER) supplements were generally avallable in 1979, and at 4 schools they were availabie on an ad hoc basis. The availability of these programs has spread rapidly over time. For the 1979 sample of twenty six schools, at the plan's early retirement age, pension wealth amounts to 5.9 times yearly earnings. At nomal retirement age, the wealthyearly earnings ratio rises to 6.0 to one, and at mandatory retirement age, pension wealth averages 6.8 times yearly earnings. By 1989, formal early retirement programs were avallable at 23 of 29 schools reporting to CoFHE, with ad hoc programs at the other 6 .

Table 2 highights the accrual of pensions and any early retirement bonuses. In calculating the accrual profiles, the table uses the average birth date and wage profiles by insticution and then weights the results by the number of tenured faculty at each institution. It can be seen from Table 2 that even though we are dealing with defined contribution plans, early retirement programs available at the schools create significant spikes in the accrual profile.

The preretirement period is the five years preceding the year before eligibility for early retirement benefits. The ER spike is computed over the year in which eligibility for early retirement berefites is obtained, and the lar spike is computed over the year before eligibility for nomal retirement berefits is obtained. Early Retirement is the period between the periods for computing the ER spike and NR spike. Finally, Late Retirement is the period between attaining eligibility for normal retirement benefits and mandatory retirement.

The sharp increments in the accrual rates reflect the attainment of eligibility for early or normal. retirement benefits, where eligibility is 
accompanied by a bonus. In one plan, for example, those retiring early receive 60 percent of yearly salary between age 62 and 65 . On average, covered individuals hired at age 35 become eligible for a supplement worth 1.5 years of salary when they reach the early retirement age.

The survey also provides information on whether the individual was working part time at the end of the survey or at the date of retirement, if earlier. If more than $10 z$ of retirements from a school are from part time work, partial retirement is assumed to be generally available at the school.

Consider now the structure of the dependent retirement variable. For many of those in the sample, it is passible to determine a sequence of outcomes for six years. For those who have retired, there is information on status just before retirement. However, the sample of retirees from cofHE schools is not a true panel. For those who were partially retired as of December 31, 1978, the duration of partial retirement is not reported. Information is not provided indicating who partially retired after having left a state in which they worked full-time and whose lifetire job at the university imolved part-time work. In an effort to distinguish partial retirees who reduced work effort from full-time from those who were only part-time employees during prime working age, the sample includes only tenured faculty. An examination of the frequencies of retirement and partial retirement between the ages of 40 and 60 , indicates that early leaving and part-time work by tenured faculty are not very important in the sample. The frequency distribution of retirement sequences for the six years covered by the survey are reported in an Appendix and in a report to the Department of Education, both of which are available on request.)

\section{Empirical Findings}

Parameter estimates from the model are presented in Table 3, with asymptotic standard errors indicated in parentheses below each figure. $\gamma$ ard $p$ are parameters of the distribution of $\delta$ and $\epsilon$. The data were fit to males in 
cohorts born from 1909 through 1912. The estimation procedure follows Gustman and Steinmeier (1986a), with one modification. Those who tetited before 1974 were not included in the sample. Accordingly, the estimation procedure attempts to correct for selection due to prior retirements using early retirees from younger cohorts, a correction that was not required in our earlier work. The parameters are significant at standard levels ${ }^{2}$. CoFHE faculty retired later than did workers covered by the Retirement History Survey. By age $64,39 \%$ of healthy males in the RHS without a pension had left full-time work, while only $14 \%$ of all faculty in the coFHE sample had. These differences are reflected in differences in the estimated constant, but the coefficients estimated for the effects of aging are similar for the two sampies. This suggests that although, for any given opporturity set, the levels of retirements are higher in the COFHE sample, the changes in retirement rates induced by a given incentive will be similar.

Simulation is accomplished by applying monte carlo techniques. For each observation, five random draws are taken for the stochastic terms $\delta$ and $\epsilon$ in the utility function. Table 4 simulates the percentages working full and part time by age using the pensions and social security rules in place during the sample period. The percentages resulting from a simple non-parametric hazard model are presented for comparison. The model simulates the substantial drop in work effort during the period fairly we11, although it has some trouble capturing the large increase in part time work after age 65.

Table 5 presents the results of simulations which raise the mandatory retirement age, holding other aspects of the compensation profile the same. The first column in the table uses the actual mandatory retirement ages observed in the sample, while the following two columns raise the minimum mandatory retirement age to 70 and eliminate it, respectively. Reflecting the frequency with which individuals worked until mandatory retirement, as reported in Table 
1, these simulations suggest massive increases in full time work by faculty members in their late $60^{\prime} \mathrm{s}$ and early $70^{\prime} \mathrm{s}$. As a word of caution, the simulations in column 3 take us outside the age range of observation for those in the sample. For that reason, and because we do not have information on health status, those results should be interpreted with some care.

Table 6 reports the effects of early retirement supplements in conjunction with the observed 1989 pension plans, all of which specified age 70 as the mandatory retirement age. The first column simulates the plans with no early retirement supplements, and the second column includes the observed supplements for each school. A comparison of the two columns indicates that if the early retirement provistons in the pensions available in 1989 were abolished, there would be little overall effect on observed early retirement behavior. These incentives are weak enougt that on average they had little discernible impact on retirement outcomes.

The thixd colum of the table examines the effects of unformly adopting one school's 1989 early retirement plan, which provides up to 40 percent ( $1.33 \%$ per year of service) of salary either up to five years or until age 70 , whichever is sooner. For this plan we find that there is some further reduction in full time work by faculty over 65 , but the effect is relatively stall. Thus early retirement incentive plans do not appear to be very effective, at least in the COFHE schools.

When the costs of the retirement plan are simulated; three elements are of importance: the rent paid to those who would have retired at younger ages on the basis of unchanging retirement behavior; the reduction in costs due to accelerated retirement by some highiy paid faculty; and the costs of replacement faculty. Our calculations (shown in the appendix, available on request) indicate that rents exceed the savings due to early retirement, so that even ignoring the costs of replacement faculty, this type of early retirement 
incentive plan will not be cost saving.

\section{Conclusions}

The data used in this study are old, are not strictly longitudinal, are missing key pieces of information, on health status, family structure, field of specialization, and post-retirement behavior outside the primary employer, and apply only to a limited and not representative sample of colleges and universities. These limitations mean that the findings from this study should be applied with caution. Nevertheless, the preceding analysis indicates the feasibility of adapting recent innovations in the retirement literature for analysis of retirement policies by institutions of higher education.

Simulations suggest that for the COFHE schools, extending and then eliminating mandatory retirement will lead a significant number of faculty to postpone retirement.

Some institutions of higher education are considering early retirement incentive programs which will have costs and benefits that are very sensitive to the induced retirement responses. For these plans to be cost saving, the savings from inducing earlier retizement by higher paid senior faculty must exceed the costs from rents accumulating on the basis of unchanging retirement behavior and replacement costs. Our calctlations suggest they will not. An obvious alternative option which might be considered in an effort to influence faculty retirenent is the adoption of a defined benefit plan, which is offered at many public institutions of higher education, and which can create even stronger early retirement incentives ${ }^{3}$.

The effects of retirement incentives created by innovative retirement programs, the associated program costs, and implications of related policy initlatives, may all be analyzed with analytical tools that are currently available. All that is required is the availability of the required data. 
Table 1. Mandatory Retirement Frequencies

$\begin{array}{ccc}\begin{array}{c}\text { Age } \\ \text { Range }\end{array} & \begin{array}{r}\text { Percentage of Retirements } \\ \text { Which Were Mandatory }\end{array} & \begin{array}{c}\text { Number of } \\ \text { Retirements }\end{array} \\ 65-67 & 78 & 169 \\ 68-69 & 99 & 76 \\ 70-72 & 97 & 35\end{array}$

Table 2. Increment In Pension Wealth And Early Retirement Bonus/ Earnings

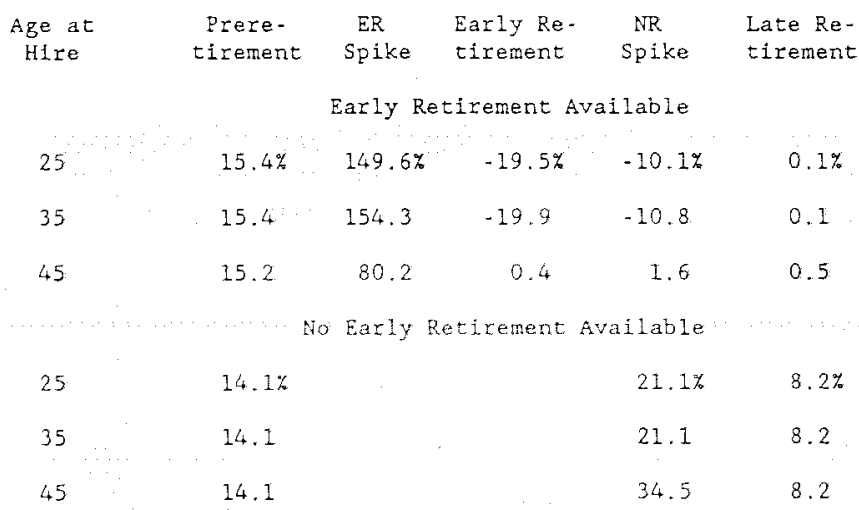

Table 3. Parameter Estimates of Utilicy Function

$\begin{array}{llrl}\gamma \quad \text { Parameter: } F(\delta)=e^{\gamma(\delta-1)} & 0.19 & (77.39) \\ \sigma_{\epsilon} \quad \text { Standard Deviation of } \epsilon & 2.17 & (18.27) \\ \rho \quad \text { Parameter: } E(\epsilon \mid \delta)=\rho(1-\delta) & -4.46 & (19.78) \\ \beta_{0} \quad \text { Constant in } \beta & 7.81 & (12.40) \\ \left.\beta_{1} \quad \text { Coefficient of (Age }-62\right) \text { in } \beta & 0.26 & (5.01) \\ \text { Observations of Vintage } 1909-12 \text { Individuals } & 273 \\ \text { Number of Weighted Observations } & 337 \\ \text { Log. Likelihood } & -407.78\end{array}$


Table 4. Actual and Simulated Employment Percentages

\begin{tabular}{|c|c|c|c|c|}
\hline & \multicolumn{2}{|c|}{ Actual Percentages } & \multicolumn{2}{|c|}{ Simulated Percentages } \\
\hline Age & Full Time & Part Time & FuIl Time & Part Tine \\
\hline Range & Work & Work & Work & Work \\
\hline $62-64$ & $87.6 \%$ & $3.9 \%$ & $76.6 \%$ & $5,9 \%$ \\
\hline $65-67$ & 38.9 & 15.0 & 38.6 & 7.1 \\
\hline $68-69$ & 12.7 & 12.7 & 17.2 & 6.2 \\
\hline $70-72$ & 1.6 & 5.6 & 6.2 & 4.0 \\
\hline
\end{tabular}

Table 5. Effects of Raising Mandatory Retirement Age

$\begin{array}{cccc}\begin{array}{c}\text { Percentages Working Full Time with } \\ \text { Actual } \\ \text { Mandatory } \\ \text { Retirement } \\ \text { Age }\end{array} & \begin{array}{c}\text { Mandatory } \\ \text { Retirement } \\ \text { Range Set to }\end{array} & \begin{array}{c}\text { Mandatory } \\ \text { Retirement } \\ \text { Eliminated }\end{array} \\ 65-67 & \begin{array}{c}70 \\ 58.6 \%\end{array} & 65.6 \% & 64.7 \% \\ 70-72 & 17.2 & 53.8 & 53.0 \\ 6.2 & 6.2 & 43.4\end{array}$

Table 6. Effects of Early Retirement Supplements Percentages Working Ful.1 Time with 1989 Pensions No Early Actual Early Uniform Early Retirement Retirement Retirement Supplements Supplements Supplements
$65-67$
$66.7 \%$
$65.9 \%$
$64.4 \%$
$68-69$
55. I
53.7
51.0 


\section{Footnotes}

* Dartmouth College, Hanover N.H. 03755 and National Bureau of Economic Research, Cambridge Mass. 02138; and Texas Tech University, Lubbock Texas 79409. We are grateful for data provided by Katharine H. Hanson of the Consortiun For Financing Higher Education, to Euysung Kim, Scott Miller and Fony Suryapranata for able research assistance, to The Department of Education for research support, and to Steven Venti, Olivia Mitchell and $W$, Lee Hansen for comments. This paper is part of the NBER programs in Labor Studies and Aging. Any opinions expressed are solely those of the authors.

1. Although our estimates assume that partial retirement involves a reduction in official hours at work, it is also possible that minimum hours constraints may be less binding in academia than elsewhere.

2. There were five observations in which individuals recired the year before becoming eligible for early retirement bonuses worth an additional one or two year's salary. In a model such as the one used in this paper, such an event would occur only if the coefficient on age in the utility function were implausibly high, implying almost no response of retirement behavior to economic incentives. Since these five retirements may well be due to health problems which, in the absence of information on health status, cannot be controlled for, and since these observations would dominate the results if they were included, these five observations are uxcluded from the sample.

3. Defined benefit plans may carry special risks for those private institutions which are highly dependent or endowment income, and thus face correlated risks in insuring their faculty against variation in returns to pension assets because low returns may occur when the institution is least able to pay. Moreover, implications of defined benefit plans for penalties to mobile faculty, who face an up or out system, should be more carefully analyzed than they bave been in the higher education literature. 


\section{References}

Blackburn, John 0., and. Schiffman, Susan, "Faculty Retirement at The COFHE Institutions: An Analysis of The Impact of Age 70 Mandatory Retirement and Options For Institutional Response", Washington, D.C.: Consortium On Financing Higher Education, May, 1980.

Fields, Gary S, and Mitchel1, Olivia, Retirement, Pensions and Social Security, Cambridge: MIT Press, 1984.

Gustman, Alan. L. and Steimeier, Thomas L., "The 1983 Social Security Reforms and Labor Supply Adjustments of Oldet Individuals in the Long Run," Journal of Labor Economics, April 1985, 3, 237-253.

Gustman, Alan L. and Steinneier, Thomas L., "A Structural Retirement ModeI", Econometrica, May 1986a, 54, 555-584.

Gustman, Alan L, and Steinmeier, Thomas L., "A Disaggregated Structurai Analysis of Retirement By Race, Difficulty of Work and Health", Review of Economics And Statistics, August $1986,67,179-185$.

Gustman, Alan I. and Steinmeier, Thomas L., "Changing The Social Security Rules For Workers over 65", Industrial And Labor Relations Review, forthcoming. Lumsdaine, Robin L., Stock, James H. and Wise, David A., "Three Models Of. Retirement: Computational Complexity vs, Ptedictive Validity", xeroxed, 1990. Southworth, J. Russell, and Jagmin, Ronald A, "Potential Financial and Employment Impact of Age 70 Mandatory Retirement Legislation On COFHE Institutions", Washington, D.C.: Consortium On Financing Higher Education, 1979. 


\section{Statistical Appendix}

The Wage Equations.

The dependent variable in Table Al is full-time, nine month salary of alI tenured males under the age of 65 . Years of age and its square and years of service and its square appear as explanatory variables in all equations, and have the expected effects.

In Table Al, eight dumny variables have also been included, one for each year of probation (i.e., each year in the nontenured ranks at the institution), with the final category for 7 + years. The omitted category is a six year probation peziod. A zero probation period means that the hiring is directly into tenured status, and so forth. Lateral hires clearly enjoy significantly higher salaries.

Grouped dumy variables measuring the probation period are also interacted with the measures of years of service. These interactions suggest that while those who were hired at a more senior level clearly enjoy higher salaries, they also experience slower growth in salaries.

Twenty five school dumies group together all tenured faculty in each school. The largest and highest paying of the twenty six institutions is the omitted school. The coefficients (not shown) indicate that there are systematic and important between school differences within the CoFHE group. Although the dumm variables standardizing for institution are highly significant, there were anly relatively minor effects from omitting them from the regression, with the strongest impact on the coefficients estimated for the measures of the probationary period and the interacion of the probation measures with yeans of service.

Retirement Outcomes: Descriptive Data.

Table A2, which includes only male tenured faculty, reports on the frequencies for sequences of retirement states that are observed in the sample. 
Outcomes are reported over six observations, from the end of calerdar year 1.973 through the end of calendar year 1978 , while the age of reference used is as of 1974.

These data reveal that until age 60 , there is virtualiy no retirement. Among men, 97 percent of the 50 to 54 year olds in 1974 remain at fuli-time work through 1978. While 2.6 percent work part-time, that is about the same percent that is found at younger ages.

over the period of observation, among those 55 to 59 years of age in 1974 , the fraction remaining at full-time work over the next five years falls to 89 percent. The fraction reporting any part-tine work rises to 5.4 percent. The sharpest transitions are observed among those who were 60 to 64 in 1974, with the number remaining at fuld time work by December of 1978 falling to 33 percent. 18.1 percent in this age group report some part-time work. For those who were 65 to 69 in the first year for which reported information is available, only 2.8 percent remain at full-time Hork by December of 1978.

Consider some basic problems with the data, which we deal with in our report to the Department of Education, upon which this article is based. The RRRRER sequence does not appear in the data. That means that any facul.ty who had retired prior to 1974 will not be included fin the data. This omission is important for older faculty. Some related sequences are also censored, There are problems in determining the details of any sequence that included part-time work prior to the last period observed. If the last period of work is full. time, we assume that all previous periods were, although there may be some rare exceptions. But when the last period is part-time work, the nature of the remainder of the sequence cannot be deduced, and that means we will have no direct information on duration of partial retirement.

Also the sequences say nothing about the nature of work after leaving the 
main job. We can only attribute a default level of utility to work when not on the main Job, but cannot distinguish among individuals on the basis of activities once having left the primary emplayer.

Retirement flows (transition rates) between any two years conform to flows from the states of full-time, part-time or retired to these same three states in the following year. Reverse flows, from part-time work to full-time work and from full-retirement to part-time work and full-time work are ruled out, so that retirement is an absorbing state. Therefore, the probabilicy of being retired in a later year, given retirement in an earlier year, is 1.

As seen from the bottom rows of each panel in Table A2, there is incomplete information on all sequences which involve a period of partial retirement, and in addition, due to the scheme for data collection, anyone who retired before 1974 is lost to the sample. 
Table Al. Results of Regression of Nine Month Salary For Tenured, Full-Time Facuity under 65

Explanatory Variables

Constant
Age
Age squared
Service
Service squared
Erobation period: 0 years
Probation period: 1 year
Probation period: 2 years
Probation period: 3 years
Probation period: 4 years
Frobation period: 5 years
Probation period: 7 t years
Service $*$ o-1 years probation
Service squared * $0-1$ years probation
Service * 2 -4 years probation
Service squared * 2 - 4 years probation
Numer of observations: 4885

Coefficient (t statistic)

$\begin{array}{rr}9.21941 & (103.97) \\ 0.02742 & (6.67) \\ -0.00024 & (5.72) \\ 0.02806 & (10.52) \\ -0.00039 & (5.86) \\ 0.55148 & (21.43) \\ 0.49992 & (16.10) \\ 0.22052 & (7.46) \\ 0.19760 & (6.90) \\ 0.16211 & (5.56) \\ 0.04771 & (5.14) \\ -0.02167 & (2.47 \\ -0.02908 & (9.34) \\ 0.00055 & (5.76) \\ -0.00927 & (2.68) \\ 0.00025 & (2.57)\end{array}$

Note: Regression includes dunmy variables for each institution.

Table A2. Distributions of Retirement Sequences

\begin{tabular}{|c|c|c|c|c|c|c|c|c|c|}
\hline & $<40$ & $\begin{array}{l}40- \\
44\end{array}$ & $\begin{array}{l}\text { Age } \\
45- \\
49\end{array}$ & $\begin{array}{c}\text { in } 197 \\
50- \\
54\end{array}$ & $\begin{array}{l}55- \\
59\end{array}$ & $\begin{array}{l}60- \\
64\end{array}$ & $\begin{array}{l}65- \\
69\end{array}$ & $70+$ & $\begin{array}{l}\text { A.I } \\
\text { Ages }\end{array}$ \\
\hline FFFFFF & 97.8 & 96.3 & 97.4 & 97.1 & 89.1 & 33.3 & 2.8 & 0.0 & 87.7 \\
\hline FFFFFR & 0.0 & 0.0 & 0.1 & 0.1 & 2.3 & 14.7 & 1.4 & 0.0 & 1.5 \\
\hline FFFFRR & 0.0 & 0.0 & 0.0 & 0.1 & 1.5 & 10.5 & 4.8 & 0.0 & 1.2 \\
\hline FFFRRR & 0.0 & 0.0 & 0.0 & 0.0 & 0.9 & 9.0 & 13.8 & 0.0 & 1.3 \\
\hline FFRRRR & 0.0 & 0.0 & 0.0 & 0.0 & 0.6 & 7.3 & 17.9 & 11.1 & 1. 3 \\
\hline FRRRRR & 0.0 & 0.0 & 0.0 & 0.0 & 0.6 & 6.2 & 30.3 & 44.4 & 1.7 \\
\hline XXXXXP & 2.2 & 3.7 & 2.5 & 2.6 & 3.8 & 16.7 & 13.1 & 22.2 & 4.4 \\
\hline XXXXPR & 0.0 & 0.0 & 0.0 & 0.0 & 0.6 & 0.8 & $2 . I$ & 0.0 & 0.2 \\
\hline XXXPRR & 0.0 & 0.0 & 0.0 & 0.0 & 0.2 & 0.0 & 4.1 & 0.0 & 0.2 \\
\hline XXPRRR & 0.0 & 0.0 & 0.0 & 0.0 & 0.2 & 0.0 & 0.7 & 0.0 & 0.0 \\
\hline XPRRRR & 0.0 & 0.0 & 0.0 & 0.0 & 0.4 & 1.1 & 3.4 & 0.0 & 0.3 \\
\hline PRRRRR & 0.0 & 0.0 & 0.0 & 0.0 & 0.0 & 0.3 & 5.5 & 22.2 & 0.3 \\
\hline Counts & 991 & 881 & 803 & 686 & 530 & 354 & 145 & 9 & 4399 \\
\hline
\end{tabular}

Legend: $\quad F=$ Full-Time Work, $P$ - Part-Time Work, and $R=$ Retired 
Table A3: Simulation of Early Retirement Plan

Expected Years OF

Work As of Age 55

No Early

Retirement

Supplement

With Early

Retirement

Incentive

Described In

Text

10.83
Expected Discounted

Earnings As of Age 55

$\$ 331,688$

333,910 